\title{
TRAVESSIAS ENTRE LITORAIS: PROPOSIÇÕES PARA A SAÚDE MENTAL EM MOÇAMBIQUE
}

\author{
TRAVESÍAS ENTRE COSTAS: PROPOSICIONES PARA \\ LA SALUD MENTAL EN MOZAMBIQUE \\ CROSSING BETWEEN COASTLINES: PROPOSALS \\ FOR MENTAL HEALTH IN MOZAMBIQUE
}

\section{Yanisa Yusuf ${ }^{1}$ e Sandra Djambolakdjian Torossian ${ }^{1}$}

${ }^{1}$ Universidade Federal do Rio Grande do Sul, Porto Alegre/RS, Brasil

RESUMO: O presente artigo se constrói a partir de reflexões baseadas numa psicanálise brasileira com interface na psicologia social, com o objetivo de dialogar com a Saúde Mental de Moçambique, um país que se subjetiva numa lógica não-ocidentalizada, cujo sistema de cuidado existente há séculos provém do curandeirismo, (re)conhecido no país como Medicina Tradicional. Sendo as políticas públicas de saúde mental regidas a partir de uma visão ocidental, este estudo questionou as reformulações teóricas necessárias para a inserção de novos dispositivos clínicos no país que incluíssem o saber tradicional. Como se trata de uma travessia, optou-se pelo método de escrita de cartas para melhor contemplar o encontro entre estas duas realidades tão diferentes e ao mesmo tempo tão semelhantes.

PALAVRAS-CHAVE: Correspondências; Psicanálise; Medicina tradicional; Dispositivos clínicos.

RESUMEN: El presente artículo se construye desde reflexiones basadas en un psicoanálisis brasileño con interfaz en la psicología social, con el objetivo de dialogar con la Salud Mental de Mozambique, un país que se subjetiva en una lógica no occidentalizada, cuyo sistema de cuidado existente desde hace siglos se deriva del curanderismo, (re)conocido en el país como Medicina Tradicional. Siendo las políticas públicas de salud mental regidas dentro de una lógica occidental, se cuestionó las reformulaciones teóricas necesarias para la inserción de nuevos dispositivos clínicos en el país que incluyeran el saber tradicional. Como se trata de una travesía, se optó por el método de escritura de cartas para mejor contemplar el encuentro entre estas dos realidades tan diferentes y al mismo tiempo tan semejantes.

PALABRAS CLAVE: Correspondencia; El Psicoanálisis; Medicina tradicional; Dispositivos clínicos.

ABSTRACT: This article is built on reflections based on a Brazilian psychoanalysis with an interface in social psychology, aiming to integrate it into the Mozambican Mental Health. Mozambique is a country that operates in a non-westernized logic; with a care system that for centuries has come from healing practices, known in the country as Traditional Medicine. As public mental health policies are governed by a Western perspective, a question was raised about the theoretical reformulations that might be necessary for the insertion of new clinical devices in the country, including traditional knowledge. Being a traverse, the method of writing letters was chosen to better contemplate the encounter between these two realities, so different and yet so similar.

KEYWORDS: Correspondences; Psychoanalysis; Traditional medicine; Clinical devices. 


\section{Introdução}

Esta escrita foi fruto de uma dissertação de mestrado produzida nos contornos de uma travessia que se fundamenta no encontro entre a psicologia moçambicana e a psicanálise brasileira com interface na Psicologia Social. Desafiada a pesquisar sobre uma clínica capaz de dialogar com as especificidades de um povo único e singular, como o moçambicano, me pareceu necessário questionar sobre a saúde mental moçambicana, inspirada em modelos ocidentais, e sua relação com a medicina tradicional, prática de cuidado com o outro existente há milênios no continente africano.

Através de cartas dirigidas a pessoas que compuseram este caminho comigo, bem como de entrevistas com os vários profissionais de saúde e de cuidado que se dedicam à escuta do sofrimento em minha terra natal, me propus a pensar numa interlocução entre a Medicina Tradicional e os saberes provenientes de uma lógica ocidental, para que se possam construir práticas de cuidado capazes de dialogar com a cultura moçambicana. A opção por escrever cartas conversa com a ideia desta travessia, que fui percorrendo tantas vezes entre Brasil e Moçambique, já que as cartas são textos que também viajam de um lugar para o outro, conectando interlocutores de mundos e universos diferentes. Além disso, por seu caráter itinerante, a escrita em tal formato me permitiu situar-me num certo lugar "entre", o que foi bastante necessário para sustentar olhares a partir de diferentes perspectivas e de circular entre esses distintos territórios que compõem a minha experiência, desde os quais emergiram as questões trabalhadas na pesquisa.

A troca de correspondências foi bastante usada em diversos campos do saber. Embora não sejam mais comuns no meio acadêmico, no passado tiveram grande importância no desenvolvimento da ciência e na construção de muitos campos de saber. Autores como Platão, Spinoza, Freud, Einstein, Guimarães Rosa, Clarice Lispector, são exemplos clássicos que, em suas respectivas áreas de influência e pensamento, constroem uma episteme viabilizada a partir desta troca (Bernardes, Tavares, \& Moraes, 2014). No campo psicanalítico, as Correspondências entre Freud e Fliess formaram uma obra de extrema importância, que estendeu-se de 1887 à 1900, e que se destacou por apresentar os primeiros passos das teorias e devaneios freudianos. De uns tempos para cá, tem-se visto no Brasil algumas publicações neste formato, num processo de construção de conhecimentos. Autoras como Anita Bernardes, Gilead Tavares e Marcia Moraes (2014), que publicaram o livro Cartas para pensar políticas de pesquisa em Psicologia. Além de Regina Benevides Barros e Eduardo Passos (2009), que trocaram cartas no formato de um diário de bordo de uma viagem-intervenção, partilhando os movimentos, pensamentos e angústias que essa viagem proporcionou.

Foucault (1983) afirma que a escrita na forma de correspondências tem um quê de criatividade e ficcionalidade: aquele que escreve converte-se em personagem. Deste modo, por conter elementos autobiográficos, a escrita epistolar é também um espaço de criação, um espaço de possibilidades para leituras diversas por leitores que se fazem interlocutores desses textos, ainda que não sejam seus destinatários originais. Assim, o exercício de escrever cartas, pelo seu caráter tão pessoal, permitiu a expressão de forma mais clara e genuína acerca da minha própria cultura, e propiciou também que eu me exprimisse e escrevesse no meu "português", mesmo que muitas vezes esteja misturado com o "brasileiro", influência inevitável após quatro anos de (con)vivência. Por isso, em alguns momentos, é o português de Moçambique que se sobressai, e, em outros, o português do Brasil. 
Nessa viagem, ao me debruçar sobre a história de Moçambique e analisar as marcas que a colonização portuguesa deixou no país, impondo suas crenças e saberes, pude refletir acerca das repercussões que essa dominação trouxe para ambas realidades - que precisaram se reinventar para existir. Fui me aproximando de uma psicanálise que no Brasil também precisou se reconstruir, levando em conta todas as singularidades deste povo. Uma vez que a psicanálise é oriunda de uma realidade ocidental, fui me perguntando sobre os desafios que culturas como a africana, com diferentes lógicas subjetivas, colocam para ela, e sobre quais reformulações seriam necessárias para a sua inserção no país. Para tal, várias viagens foram necessárias pelos mundos da Antropologia, Etnopsiquiatria, História, Psicologia Social, Literatura e Filosofia africanas, de forma que esses saberes, juntos, pudessem abrir novos horizontes para essa jornada. Posteriormente, um reencontro com Moçambique me permitiu visitar o trabalho que lá tem sido feito. Através de entrevistas com psicólogos, psiquiatras, médicos tradicionais, e escritores, foi-me possível analisar e situar-me diante das variadas formas com que os profissionais ligados à Saúde Mental se colocam perante à cultura moçambicana.

\section{Correspondências}

\section{Maputo, 3 de junho de 2013}

Queridas colegas do intercâmbio,

Estou com imensas saudades de vocês. Finalmente concluí a graduação. Pretendo voltar a Porto Alegre no próximo ano. Sei que durante as trocas no intercâmbio vocês ficaram com muita curiosidade sobre o meu país, então, através destas linhas, tentarei trazê-las para cá.

Moçambique é um país de clima úmido e tropical, situado no sudeste de África, banhado pelo Oceano Índico. Vocês iriam amar as praias paradisíacas que temos aqui. Maputo, a cidade onde nasci e cresci, é a capital. Segundo dados do Instituto Nacional de Estatística de Moçambique, o país tem 25.727.911 habitantes. Sua história foi marcada pela opressão e servidão de seu povo - imposta pela colonização portuguesa - e por uma década de conflitos armados até a sua independência, em 1975. Essa foi sucedida por um período pós-independência que veio acompanhado de uma guerra civil, a qual teve fim somente em 1992, deixando o país praticamente destruído. De lá para cá, a luta continua no resgate da sua identidade cultural.

Em relação à saúde mental do meu país, de acordo com Santos (2011), no Serviço Nacional de Saúde (Sector Público) existem 84 camas hospitalares e 5.07 médicos para cada 100.000 habitantes. Em contrapartida, existe já um sistema terapêutico de origem local que acolhe essas questões, conhecido por medicina tradicional. Segundo a Organização Mundial da Saúde (OMS, 1976), esse sistema representa "o conjunto de práticas e medidas, ingredientes e procedimentos de toda classe, sejam ou não materiais, que desde tempo imemorial, tenham permitido aos africanos proteger-se contra a enfermidade, aliviar seus próprios sofrimentos e curar-se a si mesmos” (pp. 3-4). Desde a década de 70, a OMS vem promovendo uma série de iniciativas que visam o fortalecimento e a qualificação dos saberes desenvolvidos pelas medicinas originárias de diferentes sociedades em diversos países. Além disso, também reajustou a definição do conceito de saúde para bem-estar físico, 
mental, social e espiritual (OMS, 1976), deixando aberto o desafio para o desenvolvimento de novas configurações de linhas e sistemas de saúde.

O médico tradicional é a pessoa reconhecida pela comunidade onde vive como sendo competente para prestar cuidados em saúde usando plantas, animais, minerais e outros métodos baseados em conhecimentos religiosos, sociais e culturais, além de em atitudes e crenças que prevaleçam nas comunidades. Do ponto de vista tradicional, as causas das doenças são sempre exteriores ao doente: os antepassados, os espíritos estrangeiros ou a feitiçaria, e a cura implica a participação da família. Enquanto a medicina ocidental se baseia nos fundamentos materiais da biologia, separando no ser humano o corpo do espiritual, a medicina tradicional não faz essa divisão, tratando o espiritual e o corpo em conjunto (Kotanyi, 2003).

Acredito que o país e a universidade têm feito movimentos importantes para que se assuma um resgate destes saberes, mesmo que essa mudança de paradigmas leve algum tempo para se desenrolar.

Abraço enorme, a autora.

\section{Porto Alegre, 2 de setembro de 2017}

Queridos colegas do Grupo de Pesquisa,

As tardes de quinta-feira têm sido muito importantes neste processo. O compartilhamento, as trocas, a construção coletiva e as diferentes possibilidades de olhar para o mesmo tema vêm enriquecendo as nossas produções. Estamos atravessados por uma mesma ética de "desconstrução", termo proposto pelo filósofo franco-argelino, Jacques Derrida (19302004), que questiona a ideia de verdade absoluta. O termo apresenta-se como um pensamento em constante movimento, efetuando, assim, um corte no pensamento metafísico, de modo a impedir a estagnação do mesmo. Nas palavras de Derrida: "é necessário, sem dúvida, transformar os conceitos, deslocá-los em outras cadeias, modificar pouco a pouco o terreno de trabalho, e produzir, assim, novas configurações" (Derrida, 1972, p. 30).

Assim, despida de alguns preconceitos, me permiti conhecer melhor sobre a medicina tradicional, e confesso que fiquei surpresa com a organização da sua associação, cujos representantes de cada distrito se reúnem para discutir alguns casos. Percebi que existem curandeiros com aptidões específicas para atender cada situação. A coordenadora explicou-me que o curandeiro tem a função de curar, e serve como instrumento dos espíritos dos antepassados que guiam as situações, mas nem sempre têm respostas. Os recursos terapêuticos que eles utilizam são vários, e incluem um conjunto de técnicas. O tinhlolo (um conjunto de ossos), búzios, carapaças de tartaruga, pedras, moedas, invólucros de sementes e vários outros itens acrescentados individualmente por cada um deles. Primeiro, eles fazem o diagnóstico, feito por adivinhação. Em seguida, tentam descobrir a causa por trás desse problema e, se essa for de caráter espiritual, tenta-se averiguar quem a provocou e o que deseja. Por fim, define-se a terapia a aplicar. Estes objetos são inúteis se utilizados por alguém que não integre em si espíritos que, através deles, se expressem e ajudem a interpretar a complexidade da mensagem. Para que a pessoa seja escolhida a cumprir esse papel, precisa que alguém da família também o tenha sido.

Olga, a coordenadora, recorda que se tornou curandeira há 20 anos. Nos primeiros sinais, ficou doida. "Eu senti uma pontada que eu abria a boca pra falar, tirar o ar aquilo 
seguia uma dor horrível. E me carregaram para ir ao curandeiro, não fui assim, a andar. Mas ao voltar daquela consulta, depois de dizer sim ao curandeiro, eu voltei de lá a andar.” (Trecho da entrevista com a curandeira Olga). A formação teve a duração de cinco anos, o mesmo tempo que o de uma graduação. A diferença é que o curso se dá na casa do curandeiro-mestre, e o formando tem que morar lá e se afastar da sua vida para assumir esse compromisso. É um processo difícil e intenso. Ela o descreve rapidamente, pois eles não estão autorizados a contar como se dá a formação em detalhes: "Aprendemos a bater pedras, fazer tratamento nas pessoas e vamos ao mato para tirar medicamentos e mostrar que esses medicamentos cura isto, cura isto, cura isto e também, a fazer exame do espírito." (Trecho da entrevista). Quando a professora vê que os alunos estão habilitados a exercer, ela vai embora e os deixa sozinhos para receber os clientes, fazer a consulta e seguir com o devido tratamento. A associação realiza uma formação junto com o Ministério da Saúde para aprender a identificar alguns sintomas que precisam ser imediatamente encaminhados para o hospital, como o caso da malária, cólera, HIV-SIDA, epilepsia, e alguns casos relacionados à saúde mental.

Aparece aquela pessoa que só por ver ele já está magrinho, aquele corpo... Isto tudo precisa ser diagnosticado já no hospital. Isso tudo, como já conhecemos as características das pessoas com malária, perguntamos: tem fome? Tem diarreia que não para? Então, isso é imediato. Porque nós, africanos, temos nosso problema africano, problema espiritual, problema de espírito. A pessoa, a primeira coisa que pensa quando levanta é: eu tenho que ir ao curandeiro. (Trecho da entrevista com a curandeira Olga)

Aproveitei para lhe questionar se não havia pessoas que iam só pela necessidade de falar e ser escutadas. Ao que ela responde-me que é o que mais aparece, muitas vezes, tiram as pedras e percebem que a pessoa não tem nada, mas mesmo assim, elas insistem num tratamento.

Esta associação tem na sua atuação uma ética de trabalho, uma formação intensa e uma dedicação total ao paciente, que só termina o tratamento depois do "problema" resolvido, e na maior parte das vezes com sucesso. Existe bastante complexidade, comprometimento e zelo por parte desses profissionais. Sem dúvidas, a "medicina tradicional" simboliza um sistema de cuidado com o outro, que precisa ser valorizado e reconhecido.

Estou curiosa para ouvir as vossas impressões sobre tudo isto.

Agradeço todas as contribuições que estes nossos encontros proporcionam. Sem elas esta escrita não se faria possível. Com apreço, a autora.

\section{Porto Alegre, 29 de setembro de 2017}

Prezado Professor,

Em primeiro lugar, gostaria de agradecê-lo por todo o entusiasmo que manifestou perante o tema da pesquisa. Após as entrevistas efetuadas com todos os seus colegas da saúde mental em Moçambique, pude encontrar três grupos com posições diferentes na forma como relacionam a saúde mental e a medicina tradicional. Num primeiro grupo, tem psicólogos que escutam, respeitam e compreendem a crença do paciente, mas preferem 
não perguntar muito sobre isso. Outro grupo se propõe a escutar e a perguntar pela forma que a pessoa justifica e explica sobre a sua vida e o seu sofrimento, incluindo isso no processo da escuta. O terceiro grupo, que acredita na influência das questões espirituais como uma das causas do sofrimento psíquico, propõe abertura para que o paciente busque pelo curandeiro, recomendando que o paciente vá ao curandeiro e realize as devidas cerimônias de plano espiritual para, depois, retornar à terapia. Para melhorar ilustrar como esses três grupos se apresentam, optei por trazer alguns trechos das entrevistas que traduzem a relação que cada um estabelece com a cultura. De uma forma geral, averiguamos que todos os profissionais entrevistados demonstram respeito pela medicina tradicional e visam diálogo entre estes dois campos.

Na entrevista com uma das primeiras psicólogas moçambicanas, Ana Bela Ratilal, ela relata sobre a experiência de um trabalho que efetuou numa comunidade, na qual foi surpreendida por uma paciente que entrou em transe:

Então, numa certa altura nós estávamos a fazer uma formação dos pais e dos ativistas, E, de repente, uma senhora começa-lhe a sair espíritos, começa a gritar, eu comecei a transpirar ali mesmo sem saber se eu devia fugir, se devia ficar ali, ou fazer o quê, não sabia. Eu pensei 'bem OK', os outros começaram a dizer 'estão-lhe a sair espíritos', eu disse 'OK, deixa sair, qual é o problema?', continuei e não sei o quê. E a senhora depois ficou muito aliviada sem os espíritos, eu quase que desmaiei a seguir, porque transpirei tanto. É que eu não fazia ideia do que ia fazer naquela situação... No fundo no fundo eu estava a ver uma pessoa a ficar em transe. (Trecho da entrevista com a dra. Ana Bela Ratilal)

Experiências como essas levaram-na a olhar para as questões tradicionais com mais cuidado e consideração. E, com toda a sua simplicidade, ela afirma que aprendeu a ser psicóloga junto com a população, no contato com o outro, e, com muito cuidado, menciona o seu respeito em relação aos curandeiros.

No primeiro grupo averiguado, trago como exemplo a entrevista com a atual coordenadora do departamento de Saúde Mental, Lídia Gouveia, que também defende a importância do diálogo entre estas duas lógicas de tratamento. Contudo, ela argumenta que, muitas vezes, a justificativa das causas tradicionais para o sofrimento pode influenciar as pessoas a não se responsabilizarem por qualquer mudança que se proponha fazer no trabalho terapêutico. Representando assim o primeiro grupo analisado:

Porque, habitualmente se eu disser que é por uma causa espiritual que eu sou muito nervosa, não consigo controlar, eu sou uma pessoa muito triste, ou eu não tenho sorte no casamento, tenho qualquer coisa que causa sofrimento, habitualmente vai dizer: "não, porque eu tenho o nome da minha avó, e minha avó também teve uma vida igual a minha, ou porque na minha família há um problema”. Então, na verdade a pessoa não tem uma responsabilidade, um papel ativo para fazer esta mudança. (Trecho da entrevista com a coordenadora de Saúde Mental, Lídia Gouveia)

Na mesma perspectiva, alguns psicólogos que representam o grupo dos que respeitam a cultura, mas preferem não levar essas questões para dentro da sessão, afirmam que, nas situações em que a demanda dos pacientes vem traduzida como um sofrimento da 
ordem do espiritual, a estratégia utilizada é a de desconstruir esse mito dando ao paciente uma explicação de cunho científico.

Tu achas que isto é alguém que quer te fazer mal e não sei o que? Tudo bem. Mas pensa só: um quadro de ansiedade normalmente começa como? Quando estás a começar as tuas crises de pânico, o que acontece primeiro? Não sente o coração bater rápido? ... Sabe por que que isso acontece?”. "Não.”. "Não é porque o espírito tá a lhe levar e está a lhe vencer. Não. Porque isso cansa o corpo". (Trecho da entrevista com a psicóloga Palmira dos Santos)

No segundo grupo, pude averiguar profissionais que demonstram apreço pelo trabalho do curandeiro e alegam que a influência da tradição aparece em toda a população no geral:

Eu arrisco-me a dizer, no contexto clínico, o hospital de saúde primária aparece muito essas questões, e aparecem também no contexto privado. As pessoas, quando vêm até nós, principalmente com dificuldades, problemas, patologias qualquer que sejam, já vêm com diagnóstico cultural, espiritual, tradicional. (Trecho da entrevista com o psicólogo Rómulo Muthemba).

O mesmo alega que, muitas vezes, o terapeuta cria um sentimento de ambivalência no paciente ao descartar as suas crenças tradicionais: "um dos primeiros erros que nós cometemos como terapeutas ocidentais é criar uma ambivalência nos pacientes. Isto é automático. 'Faz o favor, aqui esquece isso que é tradicional, eu aqui vou tratar dessa maneira'. Aqui a crença não faz sentido" (Trecho da entrevista). Ele acredita que essas questões possam fazer parte do tratamento através da forma como o próprio paciente vê e compreende o seu sofrimento para que se possa estabelecer assim uma aliança. Por outro lado, ele nos adverte para que haja um certo cuidado e conhecimento sobre o tema a fim de avaliar melhor o que é de cunho tradicional ou não:

Porque cultura também não é estática. Estamos cheios de questões pseudoculturais que criam doenças, espalham violência, matam pessoas. Eu vou ao curandeiro e curandeiro fez um diagnóstico tradicional e diz que a causa de todos os conflitos, todos os problemas que aquela senhora tem, tem a ver com a mãe ou o pai que fez alguma coisa. As irmãs se unem e matam o pai. Temos esse caso aqui. (Trecho da entrevista)

No terceiro grupo verificado, trago como exemplo a posição do professor Hachimo Chagane, que foi coordenador do curso na época em que me formei. Ele afirma que avalia, pelo discurso do paciente, a existência de questões de ordem cultural e a possibilidade de esse se beneficiar de um atendimento tradicional

E, às vezes, com alguns pacientes, eu combinava com eles: não tem problema, vai fazer o seu tratamento e depois volta. Conseguíamos ganhar os dois. Porque quando você cria barreiras, cria obstáculos é ... Eles mentem, pois se o terapeuta quer obrigar a pessoa a reconstruir a partir de sua perspectiva, os pacientes acabam fugindo. (Trecho da entrevista com o psicólogo Hachimo Chagane) 
Baseado na mesma linha de pensamento, trago o professor Juvêncio Sarmento, que foi um dos primeiros professores a questionar sobre a cultura em que estamos inseridos e para quem dirijo esta carta. O professor também fala sobre a importância do psicólogo poder avaliar quando a questão do paciente é de ordem psíquica, emocional ou espiritual, e de o mesmo ser capaz de compreender que não tem os recursos necessários para atender determinadas situações

Então, é isto. Se eu tenho um doente que já fez mais que o número das sessões previstas, e se insisto que tem que continuar comigo, quem é o louco entre eu e ele? São estas inculcações em que a medicina moderna, por exemplo, de achar que só ela que consegue. Será que é ela que consegue? Quantas não são as vezes em que nos deparamos com situações ainda mais complexas, fazemos todo tipo de análise... e tudo mais. Tudo negativo. Mas, entretanto, o paciente continua a queixar-se. (Trecho da entrevista com o psicólogo Juvêncio Sarmento)

Bom, agradeço toda a sua colaboração diante da presente pesquisa. Mais do que nunca, percebo a importância de debatermos sobre estas temáticas no contexto da academia para que possamos nos situar melhor no âmbito da prática profissional. Vejo que aos poucos caminhamos na direção de construir uma prática de cuidado com o outro que venha de e para a nossa cultura.

Obrigada, Da sempre aluna, a autora.

\section{Porto Alegre, 8 de novembro de 2017}

Cara Paulina Chiziane,

Conhecê-la pessoalmente foi uma experiência especial, não só pela admiração que tenho por si, nem pela escritora renomada que é, mas, sobretudo, por ser uma mulher moçambicana, negra, desafiadora de tradições, que através da sua escrita exerce uma função política potente e nos dá voz. Como costuma dizer, o teu escrito serve para "descolonizar a mente do moçambicano”. Entrevistar-te foi um verdadeiro ato de descolonização.

Fiquei bastante surpresa quando começaste por me contar sobre a experiência de um "surto psicótico" que vivenciaste em fevereiro de 2012, o qual ocasionou uma internação psiquiátrica. Nas tuas palavras, esse "surto" se tratou de uma viagem: "porque eu digo, eu não fiquei doente, desculpa, eu fiz uma viagem.” (Trecho da entrevista com Paulina Chiziane). Esse sofrimento culminou na escrita do livro Nas mãos de Deus (2013). Dissesteme que essa escrita tinha como objetivo problematizar a questão das doenças mentais, que ainda é um tema de grande desconhecimento e receio em Moçambique.

A obra traz uma narrativa psicológica centrada na personagem Alice, moçambicana próxima aos 60 anos, com recursos, estudada e bem estabelecida na sociedade, que vê a sua vida mudar completamente quando começa a ouvir vozes. Esta personagem foi baseada na sua experiência pessoal, Paulina, e no contato que teve com outras mulheres internadas no mesmo período e em situações similares. A falta de um entendimento racional do que estava a passar consigo, o distanciamento e receio dos familiares e da sociedade, levam Alice à beira do suicídio. Alice, assustada e querendo desesperadamente compreender a sua situação, consulta médicos, curandeiros, igrejas, centros espíritas e até mesmo os 
maziones (seita religiosa moçambicana que mistura cristianismo com crenças tradicionais). Espíritos? Demónio? Diabo? Esquizofrenia? Demência? Foram inúmeras as nomenclaturas escutadas para explicar o seu estado.

Então, passado este período de crise, eu comecei a perceber que há um crime muito grave chamado civilização ou ocidentalização. É grave porque o conhecimento do ocidente, à partida, elimina todas as outras formas de saber, como se o saber do ocidente fosse único. (Trecho da entrevista com Paulina Chiziane)

Diante das várias questões problematizadas nesse livro, Paulina, além do distanciamento familiar devido à falta de compreensão sobre o que a personagem vivenciava e de um certo estigma em relação à saúde mental, o que me chamou a atenção foram os diálogos e observações relacionadas aos psiquiatras e psicólogos. Trago um trecho do livro que me capturou: "Eu não precisava de remédios, mas de caridade, de conforto, de outro ser humano. Queria alguém que me desse seus ouvidos por esmola.” (Chiziane \& Silva, 2013, p. 61). Em várias passagens, percebe-se a necessidade da personagem de poder ser escutada, o que não foi possível encontrar em nenhum desses espaços. "Mas o médico cuidou-me da dor e não do sofrimento.” (p. 61). São questões muito pertinentes, que refletem o Sistema de Saúde Mental em Moçambique e confirmam a hipótese de que existe demanda para espaços de escuta.

Paulina, foi um prazer enorme conhecer-te pessoalmente, escutar a tua história e experiência na primeira pessoa. Admiro a tua coragem em expores o que pensas através dos teus livros que, embora hoje não sejam valorizados pelos nossos conterrâneos, um dia, acredito eu, serão referências obrigatórias para se discutir sobre a cultura do nosso país.

Khanimambo- obrigada, de coração, a autora.

\section{Porto Alegre, 14 de março de 2018}

Querido Professor Boia Efraime Jr.,

Estou muito feliz pelo fato de teres aceitado o convite para compor a minha banca de defesa do mestrado. Estou bastante ansiosa por esse momento, acredito que a tua presença será importante não só por seres a referência da psicanálise em Moçambique - como por todo o teu percurso no país - mas principalmente por ser moçambicano.

Conforme conversamos na nossa entrevista, num momento em que me dedicava a várias leituras de diferentes universos, mencionaste o quanto a interlocução entre estas duas lógicas distintas que habitam o país se trata de um tema complexo. Tal complexidade levou-me a embarcar pelos universos da etnografia, etnopsiquiatria, e etnopsicanálise. Essa viagem ampliou consideravelmente meus modos de olhar, pensar e compreender os processos que ocorrem em nosso país e as outras possíveis perspectivas que podemos construir para ele. A etnopsicanálise "inspira-se nos princípios da psicanálise tanto os distúrbios psicopatológicos ligados a culturas específicas quanto a maneira como essas diferentes culturas classificam e organizam as doenças psíquicas" (Roudinesco \& Plon, 1998, p. 207). Tobie Natahan, um dos repercussores da etnopsicanálise, desenvolveu um dispositivo para atender imigrantes de origem africana. Nele, o indivíduo é recebido por diferentes profissionais reunidos em uma mesma sala - podendo incluir especialistas clínicos, 
especialistas da linguística (médicos tradicionais que compreendem a língua materna, os costumes e os sistemas terapêuticos locais da região do paciente) e especialistas da área psi. Nesse encontro, os profissionais e o paciente discutem horizontalmente acerca de suas leituras do sofrimento em questão, sendo o paciente o interlocutor privilegiado da análise clínica empreendida. (Roudinesco, 2005).

Apesar de ter achado um dispositivo complicado devido à quantidade de profissionais em torno de um único paciente, pressuponho um local potente e de encontro, uma vez que esses imigrantes podem ser acolhidos dentro de suas próprias tradições e terem acesso a referências de sua origem. Mesmo assim, considero essa prática oriunda de um país ocidental. Portanto, para enriquecer minha bagagem, me pareceu mais rico voltar às origens da nossa cultura. Assim, acabei me encontrando com a filosofia africana, e me deparei com uma importante referência: José P. Castiano. Baseado numa provocação a respeito da existência de paradigmas científicos em África, ele se dedicou a buscar referenciais que os sustentassem. A partir daí, começou "a defender a necessidade de nós, docentes de diferentes cadeiras, difundirmos cientistas africanos como um dos caminhos para desenvolver o gosto pelo pensamento e ciência produzidos por africanos" (Castiano, 2010, p. 11). Essa produção me levou a uma viagem no tempo para a época pré-colonial. Afinal, a história do nosso continente começou muito antes do evento da colonização, o qual deixou marcas significativas. Nesse passeio, Castiano conta-nos que desde muito cedo o "eu-africano" teve que conviver com vários "outros", que chegam pelo mar adentro carregados de produtos de troca e das suas próprias instituições religiosas e políticas. Num primeiro momento, o eu-africano reconhece o outro-asiático pelo interesse desse nas trocas comerciais. Quando esse outro-asiático chega à costa do Oceano Índico, traz na sua bagagem especiarias asiáticas e outras mercadorias. $\mathrm{O}$ interesse no encontro entre ambos estava claro: negociar. Por se tratar de uma relação de trocas, este outro-asiático deixou, sem impor, muitos rastros da sua cultura, desde a comida, passando pelo vestuário e até a arquitetura. Vestígios que se presentificam até os dias de hoje. O eu-africano mostra assim que a sua civilização era receptiva a outras culturas. "Foi a primeira prova de encontros de intersubjetivação: os povos africanos souberam abrir as suas casas e instituições culturais para acomodar, hospedar e até mesmo apropriar-se dos outros hábitos e costumes até então alheios" (Castiano, 2010, p. 196).

Este encontro horizontal com o outro-asiático se interrompeu devido a outro que surgiu em seguida: trata-se do encontro com o outro-europeu. Essa nova fusão foi de natureza política e não comercial, e destruiu os fundamentos de intersubjetividade. E assim se deu a divisão das terras africanas, em que o eu-europeu, armado de uma força brutal, com o seu exército e com a sua "aparente" superioridade científica, dividiu a terra em pedaços e as nacionalizou. $\mathrm{O}$ outro-europeu criou condições para que o eu-africano se cobrisse de um sentimento de inferioridade e rejeitasse a si mesmo, negando as suas próprias tradições e instituições (Castiano).

Castiano (2010) sustenta a ideia de que "a construção da filosofia africana se possa dar no "encontro" entre naturezas de diferentes saberes, sejam eles Deus, religião, ética, axiologia, dever, bem, conhecimento, ciência, validade, legitimação, democracia, entre outros" (p. 235). A filosofia castiana vem sendo desenvolvida como uma forma de se abrir diálogos intersubjetivos entre o saber ocidental e os saberes tradicionais africanos, colocando ambos numa relação horizontal. 
Tomando como base estas formulações, penso que podíamos, também na nossa área, apostar no diálogo entre os diferentes tipos de saber. Talvez também partilhar o mesmo espaço, produzir um encontro, uma troca, um intercâmbio, abrindo novas possibilidades, aprendendo com os recursos sociais e simbólicos, conforme sugere Broide (2015) em relação aos contextos sociais críticos brasileiros. Desta forma, então, dividir os diferentes pontos de vista em relação à mesma realidade, identificando e reconhecendo os limites de cada um. Articular campos tão amplos, compostos de diversas abordagens, que nem sempre conversam entre si, não é tarefa fácil, mas acredito ser uma saída viável para toda essa complexidade.

Essa posição levou-me à entrevista com Mia Couto, escritor moçambicano. Como o contador de histórias que é, fechou a entrevista com uma belíssima narrativa. Mia contou sobre um trabalho que efetuou em 2008, numa região do norte de Moçambique, onde as pessoas não falavam português, e a rádio que escutavam era da Tanzânia. Essa comunidade nunca havia trabalhado para alguém, pois vivia de pesca e agricultura e, portanto, trabalhava para si própria. Repentinamente, apareceu ali uma multinacional que ofereceu emprego e instrução à metade das pessoas daquela população. Algum tempo depois, a empresa alegou que era impossível empregá-las, porque eles eram preguiçosas, mentirosas e não queriam trabalhar. Mia se perguntou qual seria o equívoco. Então, foi lá e falou com o chefe das comunidades locais, que afirmou que os seus conterrâneos nunca tinham faltado ao trabalho e que os tenentes é que eram mentirosos. Explicou o homem que tinha ido na segunda-feira lá pessoalmente, e nos outros dias foram indo membros da sua família. Num dia o tio, noutro a mulher, noutro as três mulheres. Ou seja, em sua concepção, ele nunca tinha faltado, relatou Mia, porque, para ele, ele é a sua família e não existe sozinho. E isso era muito difícil de ser compreendido pelos italianos.

A mesma dificuldade pode ser encontrada pelos próprios moçambicanos, no contexto de saúde mental, no qual, muitas vezes, por estarmos estrangeiros à cultura, não a escutamos nem a compreendemos. Ao falar da sua família, o moçambicano está a referir sobre si, e muitas vezes requer uma escuta num tempo e espaço diferentes aos da lógica ocidental. Por isso, reconheço a potência da psicanálise em interface com a Psicologia Social, por ela se abrir a novos campos. Pude concordar com Rosa (2002) quando reafirma a psicanálise como um lugar de reinvenção, acreditando na transmutação da escuta psicanalítica para se poder refletir sobre alguns dos efeitos subjetivos e intersubjetivos das situações de muita pobreza e exclusão social.

Dessa forma, referente às várias posições dos profissionais de saúde que entrevistei, identifiquei-me com os que apostam no caminho do meio, que acolhem na sua escuta a demanda do paciente e o seu desejo, possibilitando a circulação da fala no seu tempo e com as suas particularidades. Mas, percebo que é preciso assumir que este é um caminho complexo. Parece que estou a ouvir-te dizer "sim, mas é complicado". Eu concordo que seja difícil, pois, ao falarmos de culturas, entramos num campo delicado e dúbio. Existem muitas situações complicadas no país que são justificadas pela tradição e cultura. Uma delas é a violência doméstica, que chega a proporções assustadoras e é muitas vezes compreendida como um ato de feitiçaria. Ou como nos exemplos que deu-me um dos psicólogos entrevistados, de filhas que matam o pai porque o curandeiro assim aconselhou; ou a perpetuação de algumas doenças como o HIV-SIDA devido a rituais tradicionais que envolvem sangue.

Como afirmaste nas nossas primeiras trocas de e-mail, há espaço sim para a psicanálise em Moçambique. Nesse "entre” de valorizar a medicina tradicional e ampliar espaços para a psicanálise moçambicana, poderíamos pensar num trabalho em conjunto? Não só 
no sentido dos diálogos, mas de forma a elaborar caminhos em conjunto que possam levar em conta as diferentes formas de tratamento que considerem as cosmovisões e práticas do povo. Poderíamos pensar nessa ampliação de campos de forma a ter médicos tradicionais na equipe de saúde mental para que, mais que diálogos, possa haver trocas intersubjetivas. Trata-se de duas realidades que circulam no mesmo campo, conversam, mas ainda não dançam juntas. Assim como Castiano (2013) propõe a entrada dos sábios tradicionais africanos nas universidades, porque não propor a entrada dos mesmos no sistema de saúde? Essas indagações, na verdade, não necessitam de respostas, são apenas especulações de uma jovem sonhadora que acredita na potência da alteridade.

Como se diz na nossa terra: estamos juntos. Com admiração, a autora.

\section{Conclusão}

No encontro com o Brasil, me deparei com uma psicanálise implantada nos espaços de saúde mental e ativa na construção de políticas públicas. Instigada por isso, apostei em possibilidades de inseri-la na realidade moçambicana, tendo como princípio que existe no país dois sistemas de cuidado que buscam um diálogo entre si. Assim, junto com os profissionais de referência na saúde mental moçambicana, pude averiguar sobre como esta relação vem se estabelecendo. Desta feita, se detectou três grupos com diferentes posições na forma como relacionam a saúde mental e a medicina tradicional. Num primeiro grupo, encontrei profissionais que respeitam as práticas tradicionais, mas acreditam na necessidade de se desconstruir algumas cosmologias para responsabilizar o sujeito no seu sofrimento. Num segundo grupo, alguns profissionais apostam que se incluam as questões tradicionais no espaço de escuta, de forma a acolher o paciente com as suas crenças, sem com isso se criar um sentimento de ambivalência nos mesmos. No terceiro grupo, além de se acolher o sujeito com as suas crenças, os mesmos são encaminhados para os curandeiros de forma a cuidar da questão espiritual e depois retornar a terapia. No Brasil, pude encontrar algumas experiências que nos concedem referências importantes que selecionei como exemplos para pensar sobre essas interlocuções.

No projeto "Soro, Raízes e Rezas" (Paulics, 2003), se buscou mesclar o saber científico ao saber popular, procurando atender às necessidades médicas e espirituais presentes na cultura daquela população. Para tal, foram realizados encontros entre os profissionais da saúde pública e as rezadeiras, com o intuito de trocar experiências que pudessem ser aplicadas em conjunto para sanar os problemas mais críticos da saúde pública daquela região. Dentre os maiores desafios desse projeto, destacou-se a dificuldade de tornar ambos os saberes (medicina tradicional e científica) complementares um ao outro, uma vez que se observou uma forte competição entre ambos. Porém, ao analisar a demanda da comunidade, percebeu-se que essa recorria, na maior parte das vezes, ao saber das rezadeiras. Diante disso, foi necessário definir a atuação de cada um dos profissionais e sua importância no processo de cura, criando-se assim espaços de trocas entre ambos. Outro exemplo se deu num recinto hospitalar, onde foi cedido um quarto para o pajé, com o intuito de acolher a cultura dos índios presentes nessa região, que afirmavam não se contentar com a medicina dos brancos. Desta forma, a população pode ter acesso aos dois sistemas de saber vigentes no local, onde cada um trabalha dentro da sua especificidade (Cassol, 2011). 
Iniciativas como estas me ajudaram a pensar em caminhos para Moçambique: valorizar a cultura local para que essa possa se inserir no tratamento conjuntamente com o método aprovado e reconhecido pelo sistema de saúde pública - o ocidental. Com isso, aposto na inserção da medicina tradicional na saúde mental de Moçambique, para que a população possa ter acesso a ambos os sistemas vigentes de cuidado, onde cada um seja capaz de exercer a sua prática, visando o bem-estar do sujeito. Por fim, esse foi um dos aprendizados que a psicanálise à brasileira, na sua construção com a psicologia social, me transmitiu: apostar nela, considerando a potência da sua dimensão política, que desafia-nos a questionar, a desconstruir e a repensar a sociedade.

\section{Referências}

Barros, R. B. \& Passos, E. (2009). Diário de bordo de uma viagem-intervenção. In E. Passos, V. Kastrup, \& L. Escóssia (Orgs.), Pistas do método da cartografia: pesquisaintervenção e produção de subjetividade (pp. 172-200). Porto Alegre: Sulina.

Bernardes, A. G., Tavares, G. M., \& Moraes, M. (Orgs.), (2014). Cartas para pensar políticas de pesquisa em Psicologia. Vitória: EDUFES.

Broide, J. (2015). A psicanálise em situações sociais críticas: metodologia clínica e intervenções (2a ed.). São Paulo: Editora Escuta.

Cassol, D. (2011, 12 de maio). Hospital gaúcho abre ala para pajés atenderem índios. Último Segundo, Rio Grande do Sul. Recuperado de http://ultimosegundo.ig.com.br/brasil/rs/hospital-gaucho-abre-ala-para-pajes-atenderemindios/n1596948776711.html

Castiano, J. P. (2010). Referenciais da filosofia africana em busca da intersubjectivação. Maputo: Ndjira.

Castiano, J. P. (2013). Os saberes locais na Academia. Maputo: Universidade Pedagógica, Centro de Estudos Moçambicanos e Etnociências.

Chiziane, P. \& Silva, M. C. (2013). Na mão de Deus. Maputo: Carmo Editora.

Derrida, J. (1972). Posições. Belo Horizonte: Autêntica.

Foucault, M. (1983). A escrita de si. In O que é um autor? (pp. 3-23) Lisboa: Vega.

Kotanyi, S. (Direção). (2003). EspíritoCorpo [Filme cinematográfico, 98 min.]. Maputo: Centro de Informação e Documentação Amilcar Cabral; Paulo Freire Instituto. Recuperado de http://www.paulofreireberlin.org/pdfs/EspiritoCorpo Brochura Kotanyi Portugues.pdf

Organização Mundial Da Saúde. (1976). Bureau Régional pour l'Afrique. African traditional medicine. Genebra: OMS.

Paulics, V. (2003). Programa soro, raízes e rezas. Instituto Pólis, 211, Recuperado de https://www.polis.org.br/uploads/653/653.pdf

Rosa, M. D. (2002). Uma escuta psicanalítica das vidas secas. Texturas: Revista de Psicanálise, 2(2), 42-46. Recuperado de http://www.revistatextura.com/leia/umaescpis.pdf

Roudinesco, E. (2005). O paciente, o terapeuta e o Estado. Rio de Janeiro: Jorge Zahar.

Roudinesco, E. \& Plon, M. (1998). Dicionário de Psicanálise. Porto Alegre: Jorge Zahar.

Santos, P. (2011) - História dos 25 anos da Saúde Mental em Moçambique. Revista Psique. MISAU, Departamento de Saúde Mental. Maputo. 


\section{YANISA YUSUF \\ https://orcid.org/0000-0002-0882-5969}

Mestre em Psicanálise: Clínica e Cultura pela Universidade Federal do Rio Grande do Sul (UFRGS); Especialista em Atendimento Clínico com ênfase em Psicanálise pela Universidade Federal do Rio Grande do Sul (UFRGS). Psicóloga Clínica pela Universidade A Politécnica em Moçambique. Maputo, Moçambique.

E-mail: yanisa.yussuf@gmail.com

\section{SANDRA DJAMBOLAKDJIAN TOROSSIAN}

https://orcid.org/0000-0002-9189-6994

Professora do Instituto de Psicologia da Universidade Federal do Rio Grande do Sul (UFRGS). Depto de Psicanálise e Psicopatologia e do Mestrado em Psicanálise: Clínica e Cultura. Porto Alegre, RS.

E-mail:djambo.sandra@gmail.com

\begin{tabular}{|c|c|}
\hline Histórico & $\begin{array}{l}\text { Sulbmissão: 10/09/2018 } \\
\text { Revisão: 01/11/2019 } \\
\text { Aceite: 14/11/2019 }\end{array}$ \\
\hline $\begin{array}{l}\text { Contribuição } \\
\text { dos autores }\end{array}$ & $\begin{array}{l}\text { Concepção: Y.Y. } \\
\text { Coleta de dados: Y.Y. } \\
\text { Análise de dados: Y.Y. } \\
\text { Elaboração do manuscrito: Y.Y. } \\
\text { Crítico revisões de conteúdo intelectual importante: S.D.T. } \\
\text { Aprovação final do manuscrito: S.D.T. }\end{array}$ \\
\hline $\begin{array}{l}\text { Consentimento de } \\
\text { uso de imagem }\end{array}$ & Não se aplica \\
\hline $\begin{array}{l}\text { Aprovação, ética } \\
\text { e consentimento }\end{array}$ & Não se aplica \\
\hline Financiamento & $\begin{array}{l}\text { Pesquisa financiada pelo CNPQ, bolsa de estudo, } N^{\circ} \text { Processo: } \\
1869615282880725 \text {; edital } N^{\circ} 10 / 2014 \text { - PEC - PG } 2014 \text {. }\end{array}$ \\
\hline
\end{tabular}

